\title{
ESTUDO DE TENDÊNCIAS DO RITMO PLUVIOMÉTRICO DA BACIA HIDROGRÁFICA DO RIO PARDO-MS
}

\author{
BEREZUK, André Geraldo - andreberezuk@ufgd.edu.br \\ Laboratório de Geografia Física/UFGD \\ GARCIA, Márcio Ribeiro - marciogarcia87@hotmail.com \\ Laboratório de Geografia Física/UFGD
}

\begin{abstract}
RESUMO. Compreender o ritmo pluviométrico de uma bacia hidrográfica é algo relevante para o conhecimento das tendências climáticas de uma determinada região. Além disso, serve para proteger e procurar mitigar uma área na qual as atividades humanas possam provocar possíveis impactos negativos, principalmente quando estes impactos se refletem sobre os setores vinculados à agricultura ou ao saneamento básico. Dessa forma, um estudo sobre tendências do ritmo pluviométrico da Bacia Hidrográfica do Rio Pardo-MS é de significativa importância para o Estado do Mato Grosso do Sul, seja porque é a bacia hidrográfica no qual está localizada a capital Campo Grande, seja porque o próprio Estado encontra-se em uma expansão dos níveis de produtividade agrícola, cuja bacia está inserida. Os dados climáticos, organizados e tabulados no presente artigo, fazem parte da monografia de Garcia (2010), correspondendo esta, ainda, a um dos poucos trabalhos realizados nessa área territorial. Estes dados, por sua vez, indicam uma tendência à maior sazonalização dos períodos secos e chuvosos, o que se constitui como uma informação importante para os Comitês de Bacia Hidrográfica do Mato Grosso do Sul e para o próprio desenvolvimento da política estadual e federal de recursos hídricos.

Palavras-chave: ritmo pluviométrico, Bacia Hidrográfica do Rio Pardo.
\end{abstract}

STUDY OF TENDENCIES OF PLUVIOMETRIC RHYTHM OF THE HYDROGRAPHIC BASIN OF RIO PARDO-MS

ABSTRACT. Understanding the rain compass of an hydrographic basin is a relevant matter to the comprehension of its climatic tendency. Besides, it is important for the protection of the area against the human activities which provoke negative impacts, mainly when they are involved with the regional agriculture or sanitation. Following this idea, the aim of this article is the researching about the tendency of the pluviometrical rhythm of the Pardo river basin, which becomes important to the State of Mato Grosso do Sul, Brazil, because two elements: its location, once the capital of the state is located inside the basin area, and the own development of the Mato Grosso do Sul State considering its agricultural production too. The climate data shown in this article were based on part of the Garcia's monograph (2010), which is one of the few researches relating this area. These data, on graphics and tables, indicate more different and marked dry and wet periods, which is an important information for the Regional Hydrographic Basins Committees and for the Brazilian politics for water resources.

Key-words: rain rhythm; the Pardo river hydrographic basin.

\section{Introdução}

A área de estudo da referente pesquisa, a Bacia Hidrográfica do Rio Pardo, constitui-se como uma área carente de dados e estudos climáticos, praticamente inexistindo, até o presente momento, uma bibliografia científica significativa de trabalhos realizados em sua região, apesar da Bacia Hidrográfica contar como município integrante a própria capital do estado, Campo Grande. Estando presente no setor oriental do Estado do Mato Grosso do Sul, a distinta bacia hidrográfica configura-se como uma sub-bacia do Rio Paraná. Sua área é de $39.419,36 \mathrm{~km}^{2}$ e possui uma população estimada em 810.964 habitantes, sendo 774.234 habitantes moradores de áreas urbanas. A Bacia Hidrográfica apresenta a composição de 11 municípios (Tabela 1), sendo dois municípios totalmente contidos nela territorialmente, que são os municípios de Bataguassu e Santa Rita do Pardo (AMORE, 2009) (Figura 1).

Também segundo Amore (2009), a Bacia Hidrográfica do Rio Pardo é a que apresenta o maior volume de água consumida no estado do Mato Grosso do Sul, devido ao consumo domiciliar e industrial de Campo Grande, sendo retiradas da bacia, em média, 2,585 $\mathrm{m}^{3} / \mathrm{s}$, mais do que os $2,068 \mathrm{~m}^{3} / \mathrm{s}$ que a bacia hidrográfica repõe. Esses dados são provenientes do abastecimento urbano das cidades da bacia. Com relação ao volume gasto pelas atividades vinculadas à irrigação, a bacia hidrográfica do Rio Pardo apresenta uma retirada de $0,390 \mathrm{~m}^{3} / \mathrm{s}$, um valor mais modesto, se comparada com a bacia hidrográfica vizinha, a do Rio Ivinhema, com a retirada de $1,046 \mathrm{~m}^{3} / \mathrm{s}$. Valores como esses revelam a importância, dos aspectos e características, da bacia hidrográfica do Rio Pardo para o Estado do Mato Grosso do Sul.

Todavia, a referente área de estudo, assim como todo o globo, está à mercê de impactos referentes a processos de alterações climáticas, em especial com a modificação dos 
regimes pluviométricos. Tal condição deve, portanto, ser considerada mediante a análise das tabelas e gráficos do referente estudo.

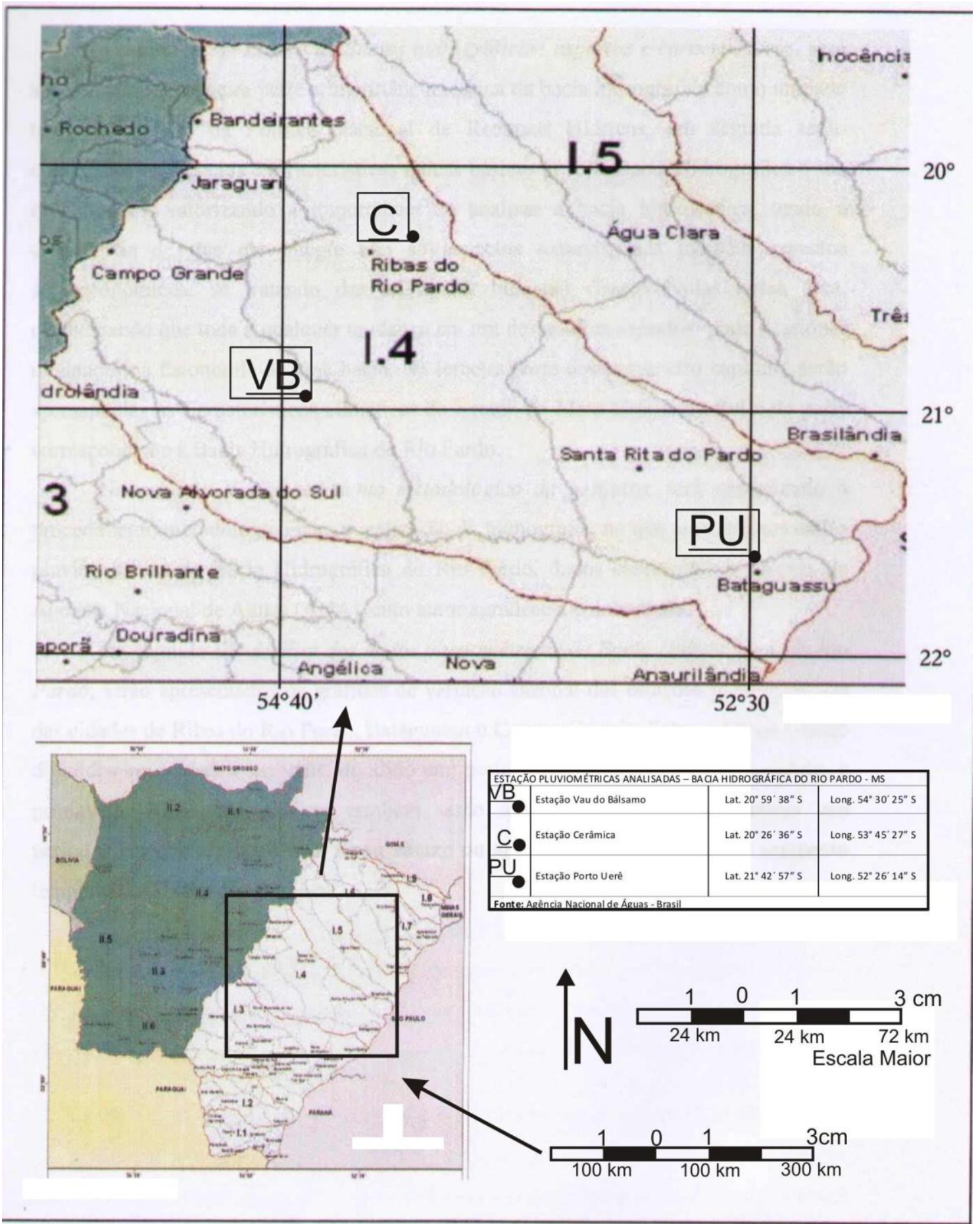

Figura 1

Área correspondente à Bacia Hidrográfica do Rio Pardo

Base: Atlas Multirreferencial do Estado do Mato Grosso do Sul (1990) 
Tabela 1

Municípios da Bacia Hidrográfica do Rio Pardo

\begin{tabular}{|c|c|c|}
\hline Municípios & Área $\mathbf{( k m} \mathbf{2})$ & $\begin{array}{c}\text { Percentual da área } \\
\text { municipal na Bacia } \\
\text { Hidrográfica (\%) }\end{array}$ \\
\hline Bandeirantes & $1.973,405$ & 63,34 \\
\hline Bataguassu & $2.416,718$ & 100 \\
\hline Brasilândia & $1.540,304$ & 26,53 \\
\hline Camapuã & 176,435 & 2,84 \\
\hline Campo Grande & $7.552,362$ & 93,28 \\
\hline Jaraguari & $2.041,734$ & 70,09 \\
\hline Nova Alvorada do Sul & $2.510,945$ & 62,47 \\
\hline Nova Andradina & $1.804,972$ & 37,79 \\
\hline Ribas do Rio Pardo & $11.911,262$ & 68,82 \\
\hline Santa Rita do Pardo & $6.141,615$ & 100 \\
\hline Sidrolândia & $1.349,773$ & 25,53 \\
\hline Total & $39.419,362$ & \\
\hline
\end{tabular}

Fonte: AMORE, L. Caracterização das Bacias Hidrográficas dos Rios Ivinhema e Pardo para a criação do Comitê da Bacia do Rio Ivinhema e do Comitê da Bacia do Rio Pardo, 2009.

\section{Procedimentos metodológicos}

Foram utilizados na pesquisa dados provenientes da Agência Nacional de Águas (ANA), correspondentes a três estações pluviométricas localizadas na Bacia Hidrográfica do Rio Pardo. Uma localizada no setor do Alto Pardo, outra no setor do Médio Pardo e a terceira na área do Baixo Pardo (Tabela 2). Todas as estações possuem dados referentes ao segmento temporal de 1977-2007, apresentando sequências de dados quase sem falhas:

Tabela 2

\section{Estações pluviométricas utilizadas na pesquisa}

\begin{tabular}{|l|l|l|}
\hline & Latitude & Longitude \\
\hline $\begin{array}{l}\text { Estação Vau do Bálsamo (município de Campo } \\
\text { Grande) }\end{array}$ & $20^{\circ} 59^{\prime} 38^{\prime \prime} \mathrm{S}$ & $54^{\circ} 30^{\prime 2} 25^{\prime \prime} \mathrm{W}$ \\
\hline Estação Cerâmica (município de Ribas do Rio Pardo) & $20^{\circ} 26^{\prime} 36^{\prime \prime} \mathrm{S}$ & $53^{\circ} 45^{\prime} 27^{\prime \prime} \mathrm{W}$ \\
\hline Estação Porto Uerê (município de Bataguassu) & $21^{\circ} 42^{\prime} 57^{\prime \prime} \mathrm{S}$ & $52^{\circ} 26^{\prime} 14^{\prime \prime} \mathrm{W}$ \\
\hline
\end{tabular}

Após a obtenção dos dados, esses foram organizados em tabelas onde se classificaram os meses com volumes mensais de precipitação entre a média e uma vez abaixo e uma vez acima o desvio padrão do período histórico analisado de cada estação (meses habituais), os meses com precipitação uma vez abaixo (meses secos) e duas vezes abaixo o desvio padrão ou com precipitação nula (meses muito secos) e os meses com volume de precipitação uma vez acima (meses chuvosos) e duas vezes acima o desvio padrão (meses muito chuvosos) do período de análise. O passo metodológico seguinte foi criar uma única figura em que se representasse a contagem dos meses citados destas três estações pluviométricas em uma única figura (Figura 2).

Além da realização das tabelas, foram realizados gráficos sazonais de precipitação em que se verificou a tendência do ritmo pluviométrico dos meses de estação chuvosa (dezembrojaneiro-fevereiro), dos meses de estação seca (junho-julho-agosto), além dos meses de outono (março, abril e maio), e dos meses de primavera (setembro-outubro-novembro) das três estações pesquisadas. Tanto a figura de contagem dos meses (Figura 2) como os gráficos sazonais de precipitação serão apresentados no decorrer do artigo. 


\section{Apresentação dos resultados obtidos e respectiva análise}

Os gráficos de análise apresentam tendência a um maior aumento dos volumes de chuvas no período chuvoso e uma diminuição do volume das chuvas de primavera, nos últimos 31 anos de análise nas estações nas relacionadas, apesar de serem apresentados dados de algumas estações que contradizem essa tendência. As tabelas, por sua vez, apresentam uma distribuição dos meses habituais e excepcionais com tendências mais conservadoras que possibilitam, conjuntamente com os gráficos, uma análise mais completa das três estações e, consequentemente, da bacia hidrográfica.

\subsection{Estação Vau do Bálsamo - Campo Grande-MS}

Segundo a análise de tendência do ritmo das precipitações da Estação Pluviométrica de Vau do Bálsamo, no município de Campo Grande-MS, o período chuvoso (DJF) segue estável em seus volumes de chuva nos últimos 31 anos de dados, sendo este responsável por aproximadamente $40 \%$ do volume de precipitação anual (Gráfico 1). Já o período de outono (MAM) apresenta uma ligeira queda de 2 a 3\% do volume de chuvas. Com relação às chuvas do período seco $(\mathrm{JJA})$, ocorreu, pelo contrário, um aumento de aproximadamente $3 \%$ de sua precipitação anual. A primavera, assim como o verão, apresentou uma tendência estável das precipitações do período.

Analisando, por sua vez, a figura onde se quantificam os meses habituais ou anômalos de precipitação (Figura 2), verificou-se uma diminuição de meses considerados chuvosos e muito chuvosos (com precipitação uma vez e duas vezes acima do desvio padrão da média histórica do período) de 42 meses, no primeiro período de análise (1977-1992), para 18 meses no segundo período de análise (1993-2007). Com relação aos meses considerados secos e muito secos (com precipitação uma vez e duas vezes abaixo do desvio padrão da média histórica do período), o primeiro período revela 28 meses secos e o segundo período 30 meses secos. A contagem desses meses, segundo esta metodologia de análise, relata a tendência, considerando os dados dos gráficos, de uma leve sazonalização das chuvas para o setor localizado no alto Pardo, já que a média anual das chuvas, para a distinta estação, apresenta-se em um nível histórico habitual para a região, (1397 milímetros de chuva anual), o que revela que não ocorreu uma diminuição significativa do volume de chuvas, mesmo com a apresentação, nos dados, dos meses chuvosos e muito chuvosos diminuírem em seu número sensivelmente. Constata-se, portanto, que a elevação do volume de chuvas dos meses de maior precipitação ficou dentro do patamar da média histórica e uma vez acima ou abaixo o desvio padrão (meses em branco na tabela), hipótese fortificada pelo aumento da porcentagem de meses habituais da estação, de 122 meses no primeiro período $(63,54 \%$ dos meses) para 132 meses no segundo período ( $73,33 \%$ dos meses), que é, inclusive, um pouco mais curto do que o primeiro. 
Meses chuvosos e secos - Estação Val do Bálsamo (1977-2007)

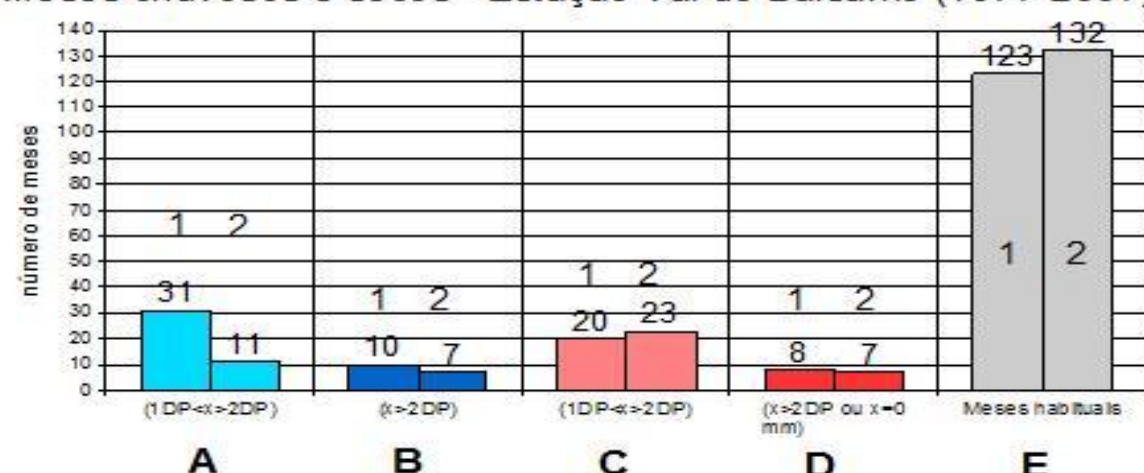

A
Meses chuvosos e secos - Estação Cerâmica (1977-2007)

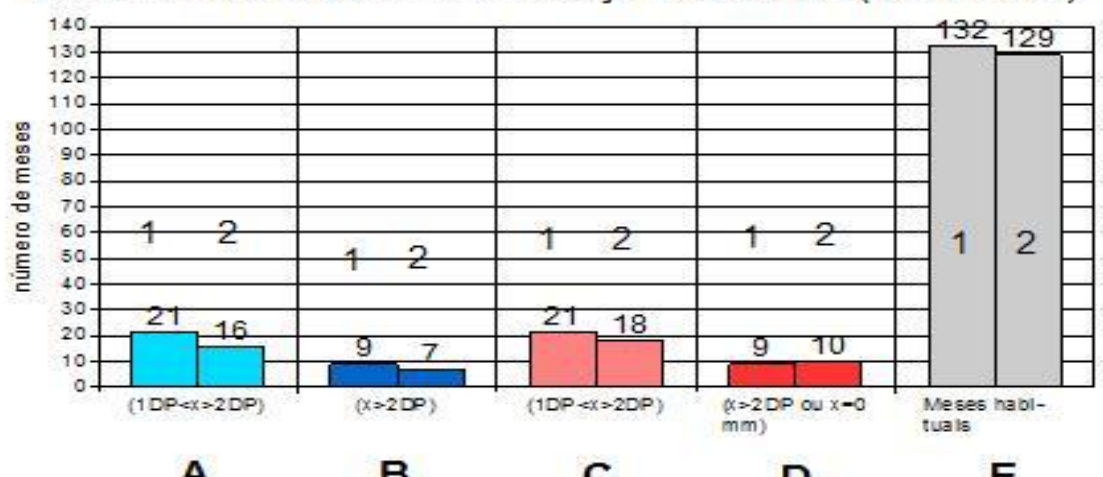

A
C
E
Meses chuvosos e secos - Estação Porto Uerê (1977-2007)

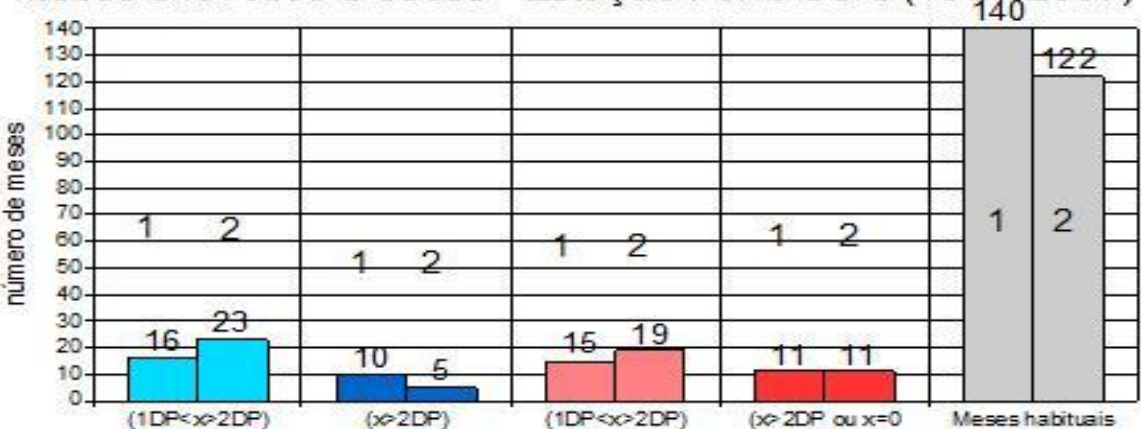

A
C
D
E
$A=$ meses chuvosos (entre uma e duas vezes acima do desvio padrão da precipitação histórica dos 31 anos analisados: $B=$ meses muito chuvosos (acima de duas

vezes o desvio padrão da precipitação dos 31 anos analisados:

$\mathrm{C}=$ meses secos (entre uma e duas vezes abaixo

do desvio padrão da precipitação histórica dos 31 anos analisados:

$\mathrm{D}=$ meses muito secos (abaixo de duas

vezes o desvio padrão da precipitação dos 31 anos analisados, ou apresentação de mês cơm precipitação zero;

$E=$ meses com faixa de precipitação habitual

$1=$ contagem dos meses entre 1977 a 1992 ;

2 = contagem dos meses entre 1993 a 2007 .

Elaboração: BEREZUK, A. G. (2012)

Figura 2. Quantidade de meses secos, muito secos, chuvosos e muito chuvosos nas estações pluviométricas de Vau do Bálsamo (Campo Grande-MS), Cerâmica (Ribas do Rio Pardo-MS) e Porto Uerê (Bataguassu-MS). 


\section{Precipitação Sazonal - Estação Vau do Bálsamo}

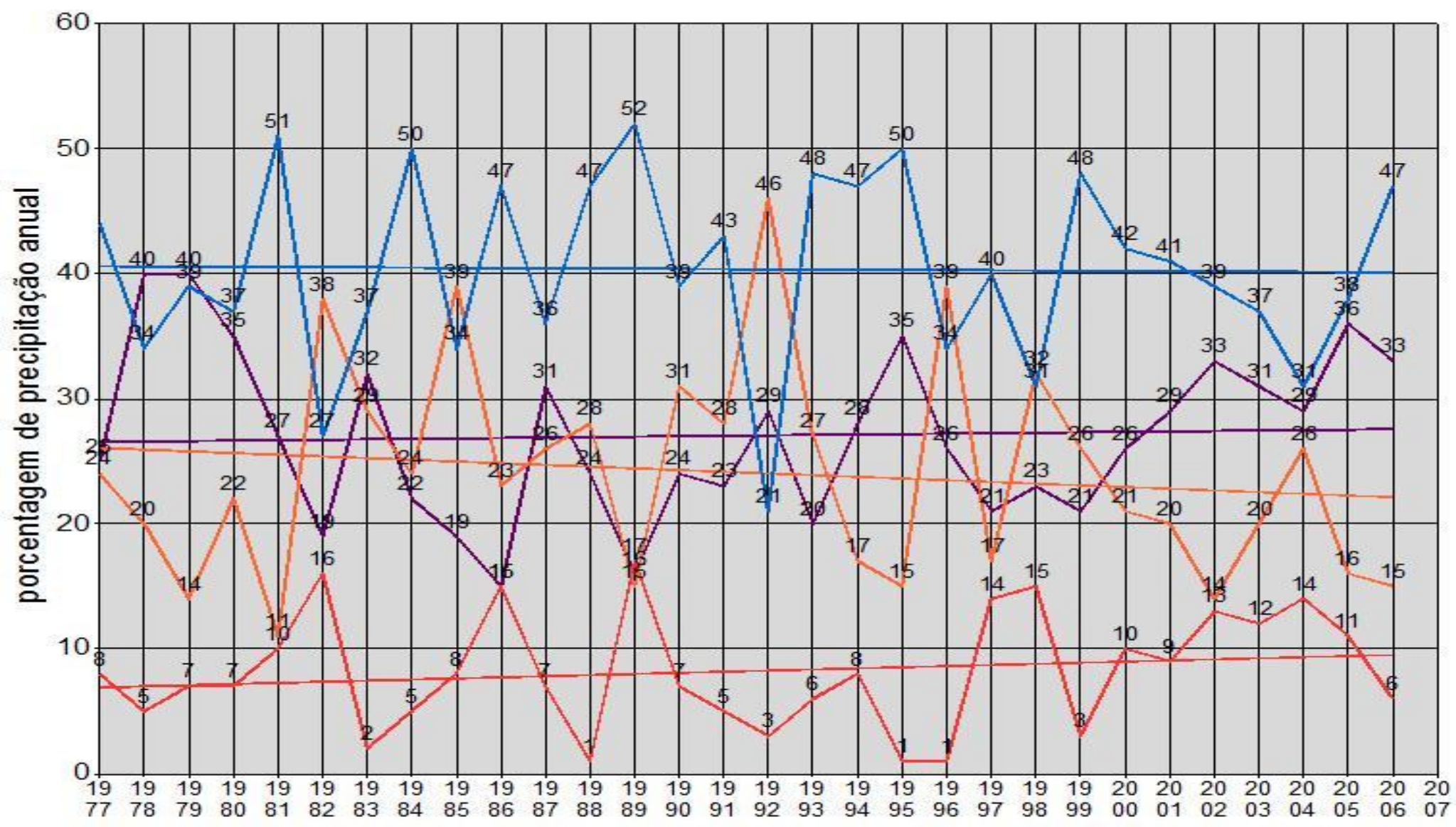

Porcentagem e linha de regressão
$\rightleftharpoons$ DJF
MAM
JJA

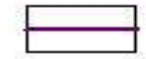
SON
Org: BEREZUK, A. G. (2012)

Gráfico 1. Porcentagens de precipitação anual das estações do ano na Estação Vau do Bálsamo - Campo Grande - MS 
Com o intuito de apresentar melhor ao leitor a complexa disposição (e natureza) dos dados, para sua melhor interpretação, convém apresentar os dados da estação sazonalmente (Tabela 3):

Tabela 3

\section{Síntese dos dados estatísticos da Estação Pluviométrica de Vau do Bálsamo - Campo Grande-MS}

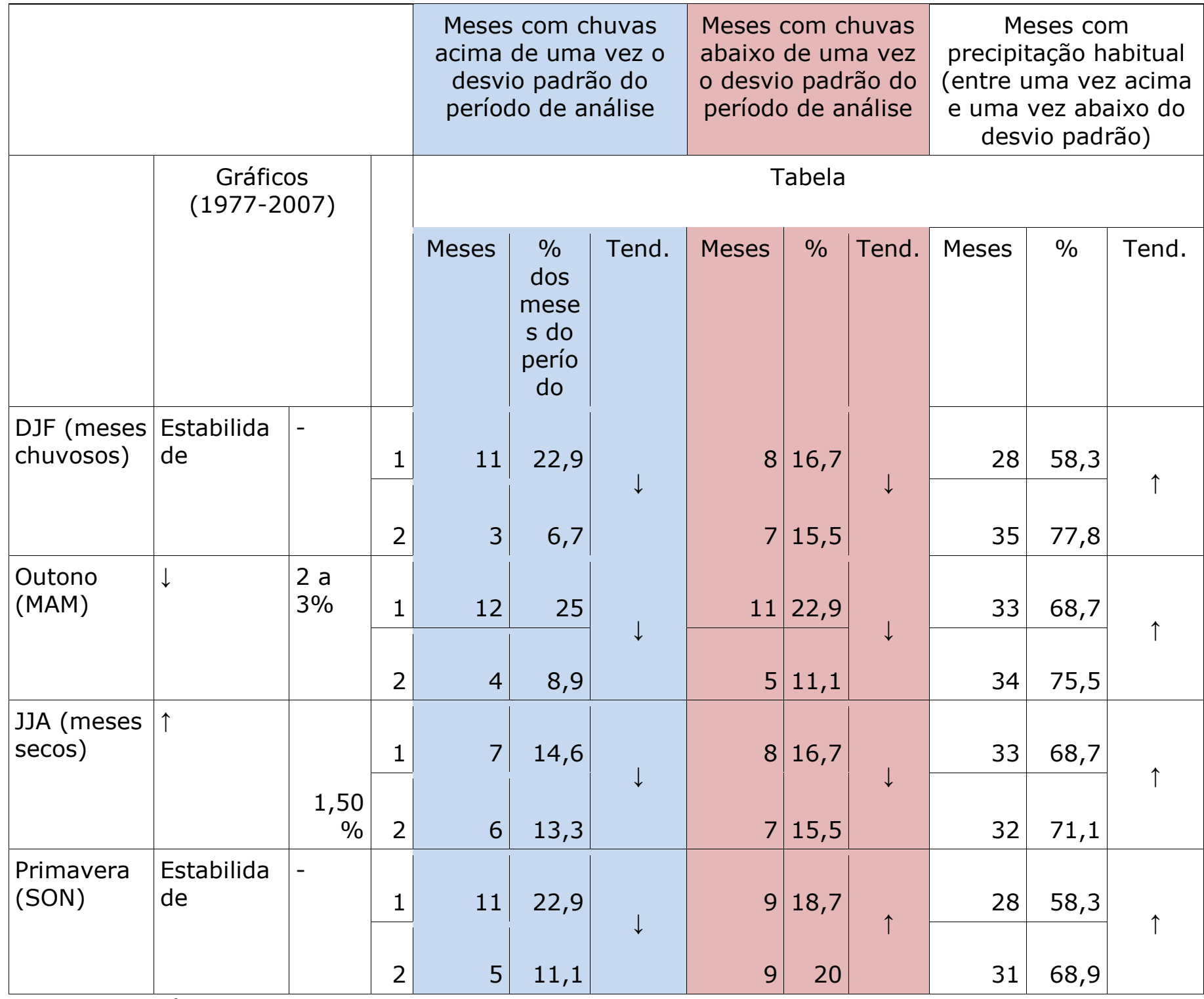

1 - Período de contagem dos meses das tabelas de 1977 a 1992;

2 - Período de contagem dos meses das tabelas de 1993 a 2007.

\subsection{Estação Cerâmica - Ribas do Rio Pardo-MS}

Com relação à tabela de quantificação dos meses da Estação Pluviométrica Cerâmica (Figura 2), entre o período de 1977-1992 foram quantificados 30 meses chuvosos e muito chuvosos e, entre o período de 1993-2007, foram quantificados 28 meses chuvosos e muito chuvosos, constituindo-se como uma tendência de queda de ocorrência desses meses, tal como na Estação Vau do Bálsamo (apesar de ser uma queda menos abrupta). Com relação, por sua vez, aos meses secos e muito secos, constataram-se 28 meses secos e muitos secos em ambos os períodos de análise. Os meses considerados habituais, assim como na Estação Vau do Bálsamo, elevaram-se, em sua porcentagem, de 69,8\% no primeiro período de análise para $71,6 \%$ no segundo período de análise. 
Tal configuração de dados da Estação Cerâmica apresenta semelhantes características encontradas na Estação Vau do Bálsamo, como a diminuição de meses considerados chuvosos e muito chuvosos, além de chamar a atenção à própria tendência de queda percentual das chuvas do período chuvoso, segundo o gráfico 2 e tabela 4. Também chama a atenção um maior número de meses anomalamente secos no período seco. Como diagnosticado na estação anterior, se ocorre uma maior presença de meses secos no período de análise e os níveis de precipitação anual continuam revelando um valor médio histórico habitual às características climáticas da área $(1428 \mathrm{~mm})$, então as chuvas seguem uma tendência de um ritmo pluviométrico dotado de maior concentração em sua intensidade, que ainda, por sua vez, não ultrapassaram os limites da estipulada habitualidade, segundo a metodologia apresentada. A seguir, o gráfico revela mais dados da Estação Cerâmica, sazonalmente: 


\section{Precipitação Sazonal - Estação Cerâmica}

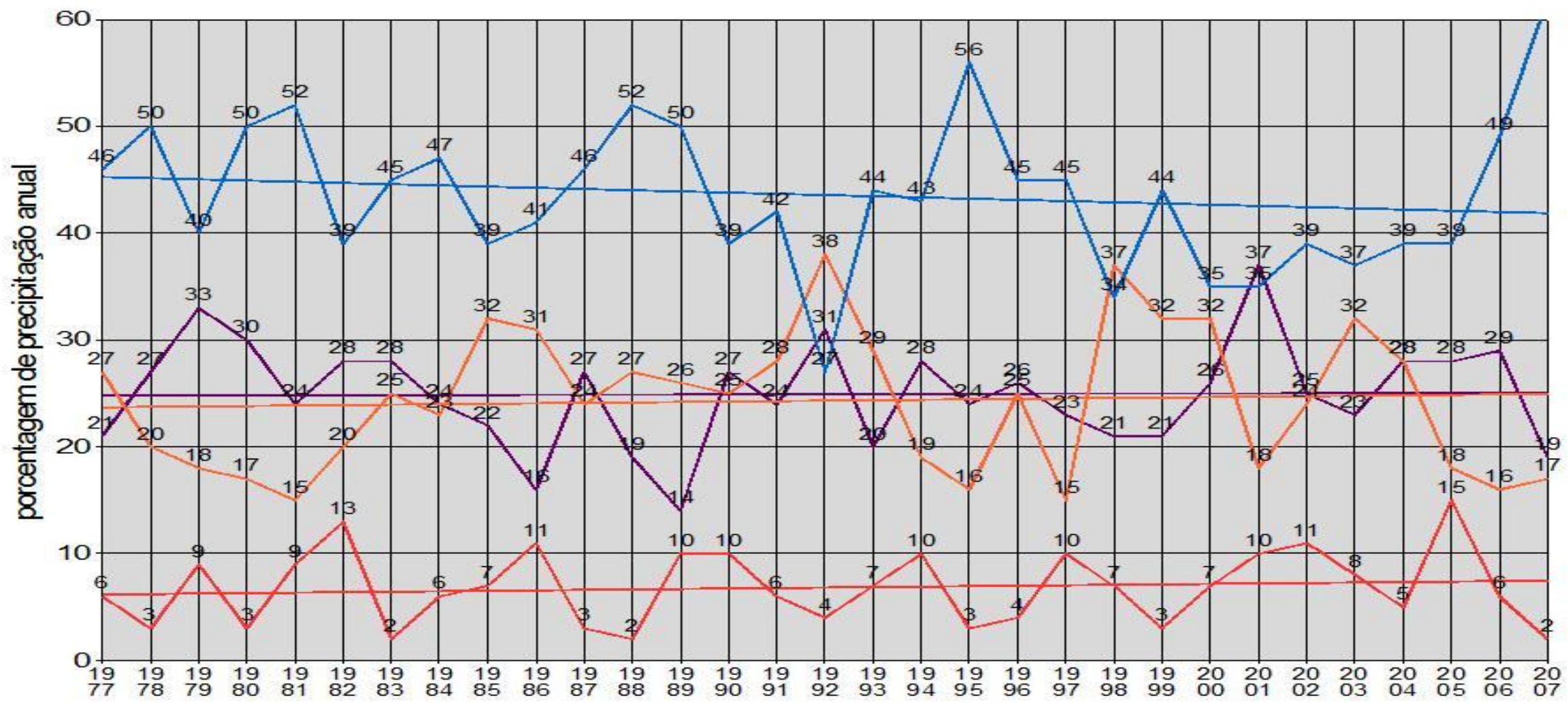

Porcentagem e linha de regressão

$\rightleftarrows$ DJF $\rightleftarrows$ MAM $\rightleftarrows$ JJA $\rightleftarrows$ SON Org: BEREZUK, A. G. (2012)

Gráfico 2. Porcentagens de precipitação anual das estações do ano na Estação Cerâmica - Ribas do Rio Pardo - MS. 
Tabela 4

Síntese dos dados estatísticos da Estação Pluviométrica Cerâmica - Ribas do Rio PardoMS

\begin{tabular}{|c|c|c|c|c|c|c|c|c|c|c|c|c|}
\hline & & & & $\begin{array}{l}\text { Meses } \\
\text { acima } \\
\text { desv } \\
\text { perío }\end{array}$ & $\begin{array}{l}\text { com chu } \\
\text { de uma v } \\
\text { o padrão } \\
\text { lo de anál }\end{array}$ & $\begin{array}{l}\text { vas } \\
\text { ez o } \\
\text { do } \\
\text { lise }\end{array}$ & $\begin{array}{l}\text { Meses c } \\
\text { abaixo } \\
\text { o desvic } \\
\text { período }\end{array}$ & $\begin{array}{l}\text { com c } \\
\text { de un } \\
\text { o pad } \\
\text { o de a }\end{array}$ & $\begin{array}{l}\text { huvas } \\
\text { la vez } \\
\text { ão do } \\
\text { hálise }\end{array}$ & $\begin{array}{r}M e \\
\text { precipit } \\
\text { (entr } \\
\text { acima } \\
\text { abaix }\end{array}$ & $\begin{array}{l}\text { ses c } \\
\text { ação } \\
\text { e um } \\
\text { e un } \\
\text { o do } \\
\text { adrãc }\end{array}$ & $\begin{array}{l}n \\
\text { abitual } \\
\text { vez } \\
\text { vez } \\
\text { svio }\end{array}$ \\
\hline & Gráf & icos & & & & & & bela & & & & \\
\hline & & & & Meses & $\begin{array}{c}\% \text { dos } \\
\text { meses } \\
\text { do } \\
\text { período }\end{array}$ & Tend. & Meses & $\%$ & Tend. & Meses & $\%$ & Tend. \\
\hline $\begin{array}{l}\text { DJF (meses } \\
\text { chuvosos) }\end{array}$ & 1 & $\begin{array}{l}\text { aprox. } \\
4 \%\end{array}$ & 1 & 8 & 16,7 & 1 & 6 & 12,5 & $\uparrow$ & 34 & 70,8 & $\uparrow$ \\
\hline & & & 2 & 5 & 11,1 & & 7 & 15,5 & & 33 & 73,3 & \\
\hline $\begin{array}{l}\text { Outono } \\
\text { (MAM) }\end{array}$ & & $\begin{array}{l}\text { meno } \\
\mathrm{s} \text { de }\end{array}$ & 1 & 7 & 14,6 & & 6 & 12,5 & & 35 & 72,9 & \\
\hline & & & 2 & 7 & 14,6 & & 6 & 12,5 & & 32 & 71,1 & \\
\hline $\begin{array}{l}\text { JJA (meses } \\
\text { secos) }\end{array}$ & & $\begin{array}{l}\text { aprox } \\
1,5 \%\end{array}$ & 1 & 8 & 16,7 & & 6 & 16,7 & & 34 & 70,8 & \\
\hline & & & 2 & 6 & 13,3 & & 9 & 20 & & 30 & 66,7 & \\
\hline $\begin{array}{l}\text { Primavera } \\
(\mathrm{SON})\end{array}$ & $\begin{array}{l}\text { Estabili } \\
\text { dade }\end{array}$ & & 1 & 7 & 14,6 & & 10 & 20,8 & & 31 & 64,6 & \\
\hline & & & 2 & 5 & 11,1 & & 6 & 13,3 & & 34 & 75,5 & \\
\hline
\end{tabular}

\subsection{Estação Porto Uerê - Bataguassu-MS}

A Estação Pluviométrica de Porto Uerê, localizada no município de Bataguassu, no setor do Baixo Pardo, apresentou uma significativa tendência de aumento da porcentagem das chuvas no período chuvoso (Gráfico 3), com aproximadamente $10 \%$ de aumento das chuvas no período de 1977 a 2007. Todavia, nos meses do período seco (JJA) e nos meses de outono e primavera, a tendência foi de decréscimo nas chuvas, segundo a tabela 5 , o que configura uma concentração das chuvas no período chuvoso e um menor volume pluviométrico nas outras estações sazonais.

Segundo a análise dos meses considerados anômalos, mediante a classificação segundo o desvio padrão do período de análise (Figura 2), a distinta estação pluviométrica é a única das três que apresentou uma diminuição do número de meses considerados habituais. No período de 1977 a 1992, foram constatados 140 meses habituais (72,9\% dos meses do período) dentro da metodologia estipulada e foram classificados, de 1993 a 2007, 122 meses (67,8\% dos meses do período). Desse modo, constatou-se uma queda dos meses considerados habituais em Porto Uerê, com o aumento de 27 para 28 meses chuvosos ou muito chuvosos e 
de 25 para 30 meses secos e muito secos, comparando os dois períodos de analise. Esse dado reforça a tendência de concentração das chuvas em períodos temporais mais curtos, exacerbando a mais clara evidência de sazonalização pluviométrica da área de estudo. De fato, das três estações pluviométricas analisadas no artigo, Porto Uerê é a que apresenta os dados mais visíveis dessa tendência de sazonalização do ritmo pluviométrico da bacia hidrográfica do Rio Pardo: 


\section{Precipitação Sazonal - Estação Porto Uerê}

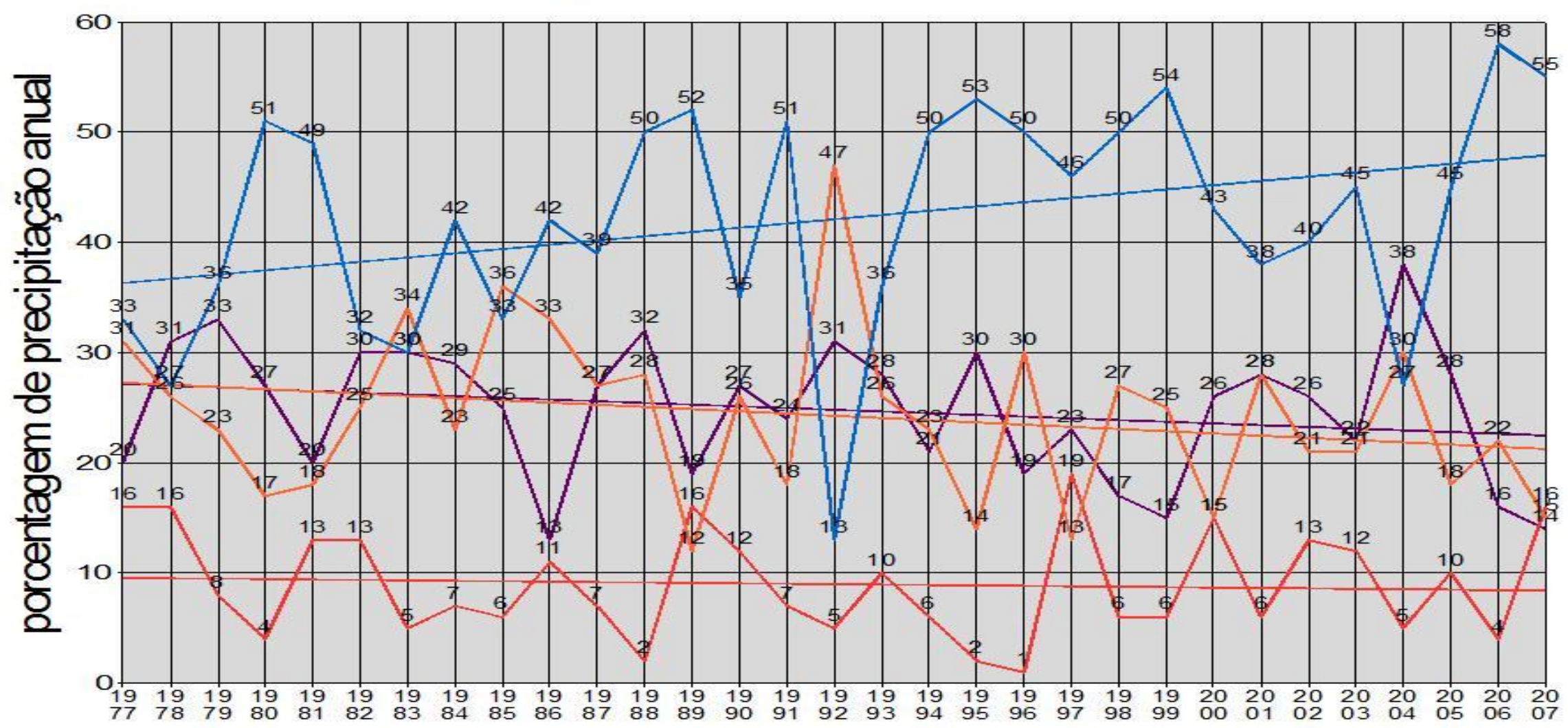

Porcentagem e linha de regressão

एDJF $\rightleftarrows$ MAM $\rightleftarrows$ JJA $\rightleftarrows$ SON Org: BEREZUK, A. G. (2012)

Gráfico 3. Porcentagens de precipitação anual das estações do ano na Estação Pluviométrica Porto Uerê - Bataguassu-MS (1977-2007) 
Tabela 5

Síntese dos dados estatísticos da Estação Pluviométrica Porto Uerê Bataguassu-MS

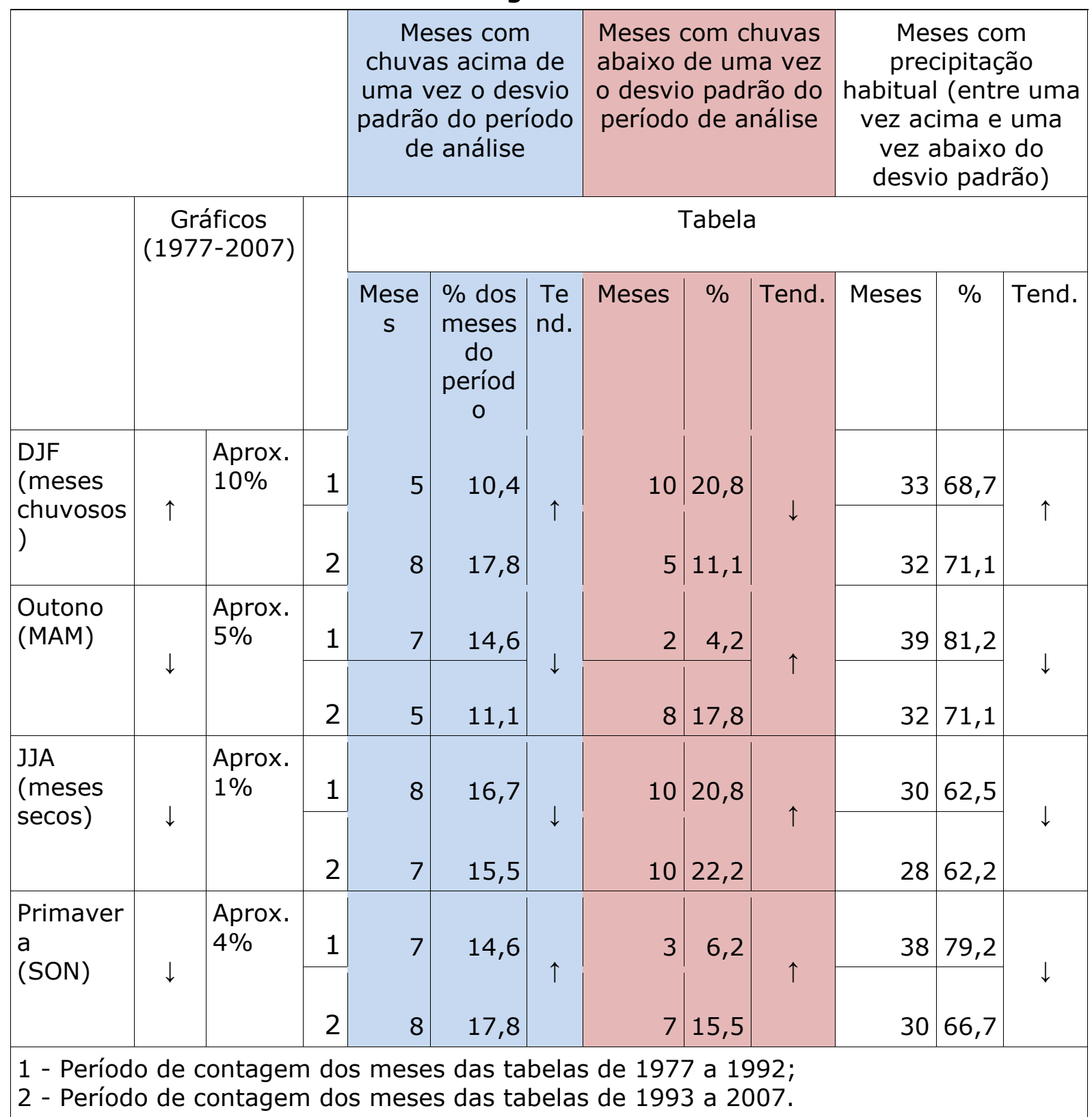

\section{Considerações finais}

Segundo os dados analisados das três estações pluviométricas, todas apresentam indícios de tendência do ritmo pluvial para uma maior sazonalização do ritmo das chuvas na área de estudo. Ou seja, com a presença de uma maior definição de períodos secos (estes até mesmo fora de sua época usual) e de ocorrência de chuvas mais concentradas, sendo que, com exceção dos dados analisados da 
estação pluviométrica de Porto Uerê, não necessariamente ocorrendo no período de dezembro-janeiro-fevereiro.

A tendência de uma maior definição dos períodos de estiagem/seca e, consequentemente, de uma maior acumulação das chuvas para a Bacia Hidrográfica do Rio Pardo corrobora apenas parcialmente com os resultados obtidos por Berezuk (2007), cujos dados revelaram, estudando o ritmo pluviométrico das Estações Meteorológicas de Presidente Prudente, Maringá e Londrina, um aumento do volume das chuvas de dezembro a fevereiro (período chuvoso) e uma diminuição das chuvas do período seco (JJA) e de outono e primavera. Os dados obtidos para as três estações da Bacia Hidrográfica do Rio Pardo, mesmo não possuindo, com exceção de Porto Uerê (baixo Pardo), rigorosamente as mesmas características similares para com os resultados de Berezuk (2007) em todos os períodos sazonais, refletem a mesma tendência.

O estudo, devido a metodologia escolhida, não possui condições de apresentar se houve mudanças nos aspectos e características de eventos extremos na área de estudo, ou mesmo se eles possuíram ou possuirão a sua intensidade aumentada. Todavia, uma maior distinção de períodos secos e uma maior concentração temporal do ritmo pluviométrico, sejam eles no período chuvoso ou não, é um quadro que remete, logicamente, a um aumento do número de eventos climáticos extremos que, porventura, poderão futuramente se converter em maior probabilidade de frequência de adversidades climáticas regionais.

\section{Referências bibliográficas}

.AGÊNCIA NACIONAL DE ÁGUAS. Brasília-DF: Dados pluviométricos diários correspondentes ao período de 1977 a 2007 das Estações Pluviométricas de Vau do Bálsamo, Cerâmica e Porto Uerê - Mato Grosso do Sul, 2010.

.AMORE, L. Caracterização das Bacias Hidrográficas dos Rios Ivinhema e Pardo para a criação do Comitê da Bacia do Rio Ivinhema e do Comitê da Bacia do Rio Pardo In: AMORE, L. Cadernos sobre a Criação dos Comitês das Bacias Hidrográficas dos Rios Ivinhema e Pardo, Estado do Mato Grosso do Sul. Brasília : Agência Nacional das Águas, UNESCO, 2009. 21 p.

.ATLAS MULTIRREFERENCIAL DO ESTADO DO MATO GROSSO DO SUL. Campo Grande-MS: Secretaria de Planejamento e Coordenação Geral, 1990. 28 p.

.BEREZUK, A. G. Análise das Adversidades Climáticas no Oeste Paulista e Norte do Paraná. Presidente Prudente-SP: Universidade Estadual Paulista "Júlio de Mesquita Filho" / Faculdade de Ciências Tecnológicas, v. 1, 2007. 379 p. (Tese de Doutorado).

.GARCIA, M. R. Estudo do Ritmo Pluviométrico da Bacia Hidrográfica do Rio Pardo-MS. Dourados-MS: Universidade Federal da Grande Dourados / Faculdade de Ciências Humanas, 2010. 49 p. (Monografia) 